\title{
Interpreting the Good Life: Growth Memories in the Lives of Mature, Happy People
}

\author{
Jack J. Bauer \\ Northern Arizona University
}

\author{
Dan P. McAdams and April R. Sakaeda \\ Northwestern University
}

\begin{abstract}
In 2 studies, the authors examined autobiographical memories for the presence of 2 growth orientations that were expected to correspond differentially to maturity and well-being, which are considered to be key facets of "the good life" by L. A. King (2001). Mature participants emphasized integrative memories (conceptual integration and learning), whereas happy participants emphasized intrinsic memories (humanistic concerns). Both kinds of growth memories correlated more strongly with eudaimonic than with hedonic measures of well-being. Growth memories were largely independent of Big Five traits in relation to maturity and well-being. Finally, older participants were more likely than younger participants to have greater maturity (marginally) and well-being, but this was in part explained by older participants' greater tendency to have growth memories. The discussion considers the role of growth memories in the intentional cultivation of the good life.
\end{abstract}

In the age-old debate over what constitutes a good life, two qualities have stood the test of time. The first is happiness. The second is meaning. Aristotle held that a particular variety of happiness was the greatest good, a happiness dealing not merely with pleasure but with the combination of pleasure and virtue. He claimed that such happiness was not easily attained, because it required considerable doses of both leisure and luck, not to mention the emotional and cognitive capacities required to balance pleasure and virtue. Although the idea that happiness and virtue go hand in hand has continued to the present day, empirical research has consistently shown that virtue-related phenomena (e.g., moral reasoning, maturity, and meaning making) hold little relationship to happiness and well-being (Flanagan, 1991). As a result, King and colleagues (King, 2001; King \& Napa, 1998; King, Scollon, Ramsey, \& Williams, 2000) have claimed that maturity and happiness represent two distinct facets of the good life. This conceptualization of the good life is more a modification than a replacement of Aristotle's view: In psychological terms, the good life seems to require a balance between thinking richly about one's psychosocial life and feeling good about it.

This view takes a eudaimonic (i.e., roughly, growth based) rather than hedonic (i.e., pleasure based) approach to the good life (Ryan \& Deci, 2001). Recently, we (Bauer \& McAdams, 2004a) situated this view of the good life in terms of personality development, noting that theories of personality development typically take one of two paths: toward social-cognitive maturity or toward social-emotional wellbeing. We represented maturity with Loevinger's (1976) construct of ego development, defined as degrees by which one can hold impulses

Jack J. Bauer, Department of Psychology, Northern Arizona University; Dan P. McAdams and April R. Sakaeda, The Foley Center for the Study of Lives, Northwestern University.

Portions of this article were presented at the Third International Conference on Memory, July 2001, Valencia, Spain. We thank the Foley Family Foundation for its major support of this research and Chris Griffin, Julie Adelman, Richard Schloe, and Brooke Smith for their ideas.

Correspondence concerning this article should be addressed to Jack J. Bauer, Department of Psychology, Northern Arizona University, Flagstaff, AZ 86011-5106. E-mail: jack.bauer@nau.edu in check, integrate multiple points of view, create meaning in a psychosocial life, and reason morally. We represented well-being with Ryff and Singer's (1998) construct of personal well-being, which includes facets tapping both personal and relational efficacy and satisfaction as well as the construct of global satisfaction with life (Diener, Emmons, Larsen, \& Griffen, 1985). In this way, the good life represents an optimal form of personality development - the capacity to think maturely and feel good about one's life in a world of others. ${ }^{1}$

The good life cannot be assessed easily by appearances. For example, increases in income and material possessions do not necessarily generate increases in maturity or well-being. ${ }^{2}$ Maturity and well-being consist largely in how one subjectively interprets and evaluates the self and others. Thus, we began a series of studies that ask, "How do mature, happy ${ }^{3}$ people think about their lives? How do they create personal meaning in their interpretations of the past and in their plans for the future?" Recently, we found that people having high levels of maturity and well-being planned their futures in terms of "growth goals" (Bauer \& McAdams, 2004a). For the current article, we hypothesized that mature people

\footnotetext{
${ }^{1}$ The fact that maturity and well-being tend not to correlate means that only a minority of the general population has attained this optimal form of personality development. However, this is a sizable minority. Approximately $25 \%$ of the population could be said to live the good life if the relationship between maturity and well-being were purely orthogonal and if high levels were defined as merely above the median levels.

${ }^{2}$ An alternative notion of the good life involves the attainment of ever-increasing wealth, for example, the American dream. However, research continually shows that increases in wealth, beyond the poverty level, do not contribute to increases in happiness (Kasser \& Ryan, 1993, 1996; Myers, 1992). Furthermore, research has shown that folk conceptions of a good life include qualities such as meaning and happiness in life but not money (King \& Napa, 1998).

${ }^{3}$ We use the term happy in a eudaimonic sense that involves, in addition to experiencing pleasure, the capacity for experiencing growth and connections to purposes and people beyond the individual self. As presented below, we measure well-being in both eudaimonic and hedonic forms (Ryan \& Deci, 2001; Diener et al., 1998; Ryff \& Singer, 1998).
} 
and happy people would frame their autobiographical memories around particular types of personal growth, which we collectively call growth memories. We then examined the theoretical traditions underlying these relationships, testing whether growth memories related to eudaimonic measures of well-being more closely than to hedonic measures. We further examined the possible role of people's broad personality traits-namely, the Big Five traits of Neuroticism, Extraversion, and Openness-in the relationship between growth memories and the good life. Finally, theory and research suggest a relationship between age and the good life. We considered the role that growth memories might play in that relationship.

\section{Maturity and Well-Being}

Several studies have compared Loevinger's (1976) measure of ego development (characterized as a combination of socialcognitive maturity, meaning making, complexity, perspective taking, impulse control, etc.) with global measures of psychological well-being and health, none of which showed a direct relationship in adulthood (Bauer \& McAdams, 2004a, 2004b; Helson \& Roberts, 1994; Helson \& Wink, 1992; Vaillant, 1977; Vaillant \& McCullough, 1987; Westenberg \& Block, 1993). In other words, people who can think maturely about their lives seem roughly as likely to be happy as unhappy.

Research has also shown that various personality constructsnotably memories, goals, and traits-tend to correspond primarily to either maturity or well-being. In research on narratives of personal memories, King et al. (2000) studied memories about parents finding out that their children had Down syndrome. The authors found that memories that emphasized the accommodation or consolidation of new information corresponded to ego development, whereas memories that emphasized happy endings and closure corresponded to well-being. Recently, we found that narrative memories of major changes in careers and religions emphasized two themes - integrative themes and intrinsic themes - that corresponded differentially and respectively to ego development and well-being (Bauer \& McAdams, 2004b). We also found that narratives of major life goals-in two forms, exploratory and intrinsic-corresponded differentially to ego development and well-being, especially when those goals were coherent with everyday goals (Bauer \& McAdams, 2004a). In nonnarrative research, McGregor and Little (1998) found that goal integrity corresponded primarily to conceptual meaning, whereas goal efficacy corresponded primarily to well-being. People with high levels of ego development have been found to have heightened levels of responsibility, tolerance, achievement (Helson \& Roberts, 1994), ego resiliency, and interpersonal integrity, but not self-ease (Westenberg \& Block, 1993). Bursik (1991) found that recently divorced women who adapted better over the course of the 1st year after divorce showed an increase in ego level, but ego level at any one time did not correlate with adaptation or global well-being. Thus, it appears that maturity operates relatively independently of happiness.

\section{Growth Memories and the Good Life}

In this section, we outline the constructs of growth memories that we expected to correspond to maturity and well-being. By examining narratives of autobiographical memories, researchers can tap into the intentions and meanings that people use to make sense of the myriad events in their lives (Bruner, 1990; Conway \& Plydell-Pearce, 2000; McAdams, 2001; Singer, 2004). Previous narrative research has used autobiographical memories of specific major life changes-but not general life stories-to differentiate maturity and well-being. Therefore, in the present two studies, we asked participants (college students and adults) to write about three significant memories in their lives: high points in life, low points in life, and turning points in life. Then we identified those memories that had growth orientations, either as integrative memories or intrinsic memories or both (see below). Finally, we compared these measures of integrative memories and intrinsic memories with measures of maturity (ego development; Loevinger, 1976) and well-being (life satisfaction and personal well-being; Diener et al., 1985; Ryff \& Keyes, 1995).

\section{Integrative Memories}

Integrative memories focus on concerns that theoretically foster social-cognitive development. Such memories involve a concern for the differentiation and integration of new perspectives on the self and others, that is, for learning about or coming to understand one's life in ever-greater richness of meaning. We derived this operational definition (see Method section) from theories and research on social-cognitive development (Bauer \& Bonanno, 2001a; Damon \& Hart, 1988; Turiel, Smetana, \& Killen, 1991; Wertsch, 1991; Youniss, 1980). These theories claim that socialcognitive development results from the differentiation and integration of information, particularly via social interaction. Following largely in this theoretical tradition, Loevinger's (1976) ego development can be described as delineating various degrees of maturity by which one can think about the self and others (or the capacity for constructing psychosocial meaning in one's life). Thus, we expected integrative memories to correlate with ego development. We also expected integrative memories to correlate with particular dimensions of personal well-being (see below; Ryff \& Keyes, 1995).

\section{Intrinsic Memories}

Intrinsic memories focus on concerns that theoretically lead to well-being. Intrinsic memories involve an emphasis on intrinsic rather than extrinsic concerns (from self-determination theory; Deci \& Ryan, 2000; Sheldon \& Kasser, 1995). Briefly, intrinsic concerns deal with humanistic pursuits such as personal growth, fostering meaningful relationships, and contributing to society. Extrinsic concerns deal with materialistic pursuits such as attaining money, status, and physical appearances. Although the three intrinsic factors - dealing with growth on the personal, relational, and societal levels - have been distinguished theoretically and empirically (e.g., Erikson, 1950/1994; Kasser \& Ryan, 1996), they have also been shown to cohere as a higher order, intrinsic construct across cultures (e.g., Kasser \& Ryan, 1996; Ryan et al., 1999). In the present studies, we considered them all as "intrinsic memories." Measures of intrinsic pursuits, notably in the form of intrinsic goals, have corresponded to well-being (Deci \& Ryan, 2000; Kasser \& Ryan, 1996; Sheldon \& Kasser, 1995). Thus, we expected intrinsic memories to correlate with well-being. 


\section{Hypothesis 1: Growth Memories, Maturity, and Well-Being}

We expected that the two kinds of growth memories would correspond to differences in maturity and well-being. Specifically we predicted that integrative memories would correlate predominantly with maturity (measured as ego development; Hy \& Loevinger, 1996), whereas intrinsic memories would correlate predominantly with two measures of well-being (Diener et al., 1985; Ryff \& Keyes, 1995).

\section{Eudaimonic Versus Hedonic Approaches to the Good Life}

In these studies, we have taken a particular approach to the good life. This approach aims beyond simply wanting pleasurable experiences in life. This approach emphasizes the individual's striving to optimize human potentials. This growth-oriented approach has been given various labels, such as organismic, humanistic, and eudaimonic. In a review of psychological theory and research, Ryan and Deci (2001) summarized the distinction between eudaimonic well-being and hedonic well-being: The hedonic approach views well-being and the good life in terms of the presence of pleasure and the relative absence of pain. In other words, wellbeing results as one gets what one wants, whatever that may be. In contrast, the eudaimonic approach views well-being in terms of self-realization and growth (which includes pleasure but is not focused primarily on it). Well-being increases as one becomes increasingly more capable of living out particular, universally beneficial human qualities (such as autonomy, competence, and relatedness; Deci \& Ryan, 2000). However, these two approaches overlap theoretically and empirically (Ryan \& Deci, 2001; Ryff \& Keyes, 1995), and we think that measures from both camps would contribute to a comprehensive understanding of the good life.

\section{Hypothesis 2}

We hypothesized that intrinsic memories would more closely correlate with a eudaimonic measure of well-being than with a hedonic measure. Growth memories were defined within the eudaimonic tradition. Growth memories derived their meaning from (i.e., placed value on) the consideration of multiple viewpoints rather than just one's own as well as from long-term growth rather than just immediate pleasure. We used two measures of well-being in the present studies: the multidimensional measure of Personal Well-Being (PWB; Ryff \& Keyes, 1995) and the Satisfaction With Life Scale (SWLS; Diener et al., 1985). These two measures come, respectively, from the eudaimonic and hedonic traditions (Diener, Sapyta, \& Suh, 1998; Ryff \& Singer, 1998). Hypothesis 1 predicts that intrinsic memories will correlate with both PWB (eudaimonic) and SWLS (hedonic) forms of well-being. However, Hypothesis 2 predicts that intrinsic memories will be more strongly associated with PWB than with SWLS.

\section{Hypothesis 3}

Integrative memories, by virtue of their emphasis on cognitive or conceptual growth, have less theoretical overlap with hedonic principles than do intrinsic memories (which generally involve pleasure but also an added focus on growth, though not necessarily a conceptual type of growth; see Method section). Thus, we hypothesized that integrative memories would correspond to particular dimensions of PWB. PWB has six dimensions: Autonomy, Environmental Mastery, Personal Growth, Positive Relationships, Purpose in Life, and Self-Acceptance (Ryff \& Keyes, 1995). We expected intrinsic memories to correlate with all six dimensions, whereas we expected integrative memories to correlate with only three (Autonomy, Personal Growth, and Purpose in Life). Those three deal with the capacity to create a conceptual understanding of abstract qualities in one's life: an understanding of one's own individuality (Autonomy), an understanding of one's development over time (Personal Growth), and an understanding of one's ties to meanings and values beyond the individual self (Purpose in Life). In contrast, the other three dimensions deal more with feelings and less with conceptual abstractions about one's life. Environmental Mastery deals with one's perceived ability to do things in the concrete world. Positive Relationships deals with the sense that one's relationships are good overall. Self-Acceptance deals with the perception that the self is good overall. Research has provided some evidence that Autonomy, Personal Growth, and Purpose in Life hold weaker (or no) ties to hedonic measures of well-being (such as positive and negative affect and SWLS) than do the other three dimensions (Ryff \& Keyes, 1995), which is not to say that the other three are "hedonic." Research has also shown that the Big Five personality trait of Openness to Experience correlates with Autonomy, Personal Growth, and Purpose in Life, but not with the other three (Schmutte \& Ryff, 1997). Openness is the Big Five trait associated most with intellection and least with affect (John \& Srivastava, 1999).

\section{Growth Memories, Traits, and the Good Life}

\section{Levels of Personality}

So far, these studies have focused on the relationship between growth memories and the good life. But what role might broad personality traits play in that relationship? In response to the idea that broad traits are the fundamental elements of personality, McAdams (1995) claimed that one cannot know a person's life story - how a person interprets his or her life-from simply knowing that person's traits. McAdams (1995) postulated three levels of personality. Level I involves broad traits (e.g., the Big Five traits). Level II involves personal concerns or characteristic adaptations (e.g., goals and motives). Level III involves life stories or personal narratives, which reveal how the individual integrates the myriad events and elements of his or her life into something meaningful. Life stories accomplish this via narrative themes (e.g., themes of agency and communion [McAdams, 2001]; themes of growth [Bauer \& McAdams, 2004b]) and narrative structure (e.g., Baerger \& McAdams, 1999; Woike, Gershkovich, Piorkowski, \& Polo, 1999). In the present studies, we were concerned with Levels I and III, which can be compared in terms of their degrees of generality and subjectivity. Traits are more general; they describe how the person thinks, feels, and acts across contexts. In contrast, life stories are more contextualized; they describe specific events, specific times, specific people, and so on. Also, traits are less subjective; a person's traits can for the most part be observed by other people. In contrast, a person's life story cannot be obtained by merely observing that person. The person's life story, as an autobiographical or subjective interpretation of his or her life, must 
be told by that person; how one makes sense of one's own life cannot be inferred from behaviors or even brief encounters with the person. According to McAdams (1995), traits and stories may share some qualities (e.g., an extraverted person may well tell personal stories of positive affect), but the ways in which a person integrates information into a personally meaningful story cannot be reduced to the information provided by traits. In other words, narratives may be related to traits but are not derivatives of traits.

\section{Hypothesis 4: Traits, Memories, Maturity, and Well-Being}

We expected that traits and growth memories would correlate but that the two would predict both maturity and well-being independently. Specifically, we predicted that the trait of Openness would correlate with integrative memories and maturity, but integrative memories and maturity would retain their relationship when controlling for Openness. We also predicted that Neuroticism and Extraversion would correlate with intrinsic memories and well-being, but intrinsic memories and well-being would retain their relationship when controlling for Neuroticism and Extraversion. (Conversely put, we predicted that traits would not mediate the relationships between growth memories and either maturity or well-being.)

\section{Growth Memories, Age, and the Good Life}

\section{Age and Personality Development}

Not only do most people find the good life difficult to attain (King, 2001), but they also may have to wait to attain it. The characteristics at the mature end of theories of personality development-for example, self-actualization, authenticity, autonomy, and integration - are typically reserved for later rather than earlier periods in life (Erikson, 1950/1994; Loevinger, 1976; Maslow, 1968). Even well-being, which can occur in any period of the life span, has been shown to come in higher degrees for older adults (notably in the reduction of negative affect; Charles, Reynolds, \& Gatz, 2001; Mroczek \& Kolarz, 1998). Yet age is not a psychological variable in the sense of thoughts, feelings, and behaviors. Chronological age explains little about the individual's influence on development. Therefore, age is merely a starting point for asking the questions of how and why psychological development ensues over time (Neugarten, 1979). Research has shown that intrinsically motivated goals account in part for the relationship between age and well-being (Bauer \& McAdams, 2004a; Sheldon $\&$ Kasser, 2001). In other words, older people have been found to have higher well-being than younger people, but this fact has been partially explained by the fact that older people are more likely to have intrinsic goals. Research has also shown that personality traits account for relationships between age and well-being beyond demographic and other life-situation variables (Mroczek \& Kolarz, 1998).

\section{Hypothesis 5: Age, Memories, Maturity, and Well-Being}

We expected that growth memories would partially account for (i.e., mediate) any relationships between age and maturity and between age and well-being. Specifically, if age correlates with maturity, then integrative memories will mediate that relationship. If age correlates with well-being, then intrinsic memories will mediate that relationship. In other words, if older participants are more likely than younger participants to be mature or happy, this fact could be partially explained by the fact that older people are more likely to have particular kinds of growth memories.

\section{Method}

The measures presented in this article were identical for the student and adult studies. For the sake of brevity, we present the two studies together rather than separately.

\section{Participants and Procedure}

The student study included 125 students at Northwestern University. Seventy-two percent of this sample was female, $33 \%$ was of a minority race, and the sample had a mean age of 19.8 years $(S D=1.0)$. For the adult study, fifty-one adults from the Evanston, Illinois area who had participated in interview-based studies previously (McAdams, 1993; McAdams, Diamond, de St. Aubin, \& Mansfield, 1997; McAdams, Reynolds, Lewis, Patten, \& Bowman, 2001) were contacted to volunteer for a written study on life narratives and were paid $\$ 150$ for participation. Seventy percent of this sample was female, $20 \%$ was of a minority race, and $80 \%$ held college degrees. The sample had a mean age of 51.7 years $(S D=10.0$; range $30-72$ ) and a median household income of $\$ 55,000$ per year. The present studies were part of a larger project on life stories in which students and adults wrote one- to two-page narratives concerning a variety of autobiographical memories and personal goals. The present studies targeted the portions of the project involving narratives of high points, low points, and turning points in life. Other measures included ego development and well-being. ${ }^{4}$ Participants completed a booklet containing these and other measures at places and times of their choosing. Booklets typically took 2-4 hr to complete.

\section{Narrative Measures}

Overview of the narrative measures. Each episode in the survey included a paragraph that instructed participants on the particular topic of that episode. For example, high points were described in the following manner: "These are generally moments or episodes in a person's life in which he or she feels a sense of great uplifting, joy, excitement, contentment, or some other highly positive emotional experience." Participants were instructed to

make sure that this is a particular and specific incident (e.g., happened at a particular time and in a particular place) rather than a general "time" or "period" in your life. Please write about exactly what happened, when it happened, who was involved, what you were thinking and feeling, why this event is significant, and what this event says about you and your personality.

Each episode was coded for the presence (scored as 1 ) or absence (0) of both integrative and intrinsic themes. ${ }^{5}$ Coders were first instructed to identify the main activity or situation at hand-what was happening behaviorally. Coders were then instructed to identify what the person claimed to be important about that situation. This latter information is what was to be coded for integrative and intrinsic memories. In other words, narratives were coded for the personal meanings of events, not the types of

\footnotetext{
${ }^{4}$ A recently published article with these two samples used these measures of ego development and well-being in relation to measures of major life goals (Bauer \& McAdams, 2004a).

5 The dichotomous nature of this coding system may seem to belie the complex nature of narratives. For example, individual narratives often
} 
events. Interrater kappa was .64 (82\% agreement rate) for integrative memories and .68 (84\% agreement rate) for intrinsic memories.

Coding for integrative memories. As mentioned above, integrative themes were derived from theory and research on social-cognitive development (e.g., Damon \& Hart, 1988). Memories with integrative themes (called simply integrative memories) emphasized the importance of learning, integrating, or otherwise coming to a new or deeper understanding about the self or others. Nonintegrative memories emphasized the experience or factual conditions of the situation but not whether one learned anything conceptual from it. In addition, coders were instructed to note the difference between showing and telling, in order to avoid the problem of scripted or vague phrases that hint at growth but give no substantial evidence of it (Loevinger, 1976). Narratives that simply told things like "I grew from the experience" or "I was transformed" were not coded for integrative themes unless the narrative showed examples of that transformation. This was conveyed by statements like, "I was transformed ... I understood what I was doing from a new point of view," or else by first describing different or conflicting points of view and then by describing how the person integrated or balanced them. For example, many turning points involved making a major life decision. Those turning points that described the psychological (often conflicting) perspectives that were considered, and then described how they were integrated or resolved, were coded for integrative themes. Examples appear in Appendix A.

Coding for intrinsic memories. Intrinsic themes also dealt with growth but were derived from theory and research on self-determination theory (Deci \& Ryan, 2000). Memories with intrinsic themes (called simply intrinsic memories) emphasized the importance of personal growth, meaningful relationships, and contributing to society. Nonintrinsic memories emphasized extrinsic concerns like the importance of money, status, approval, and physical appearance, or else nonintrinsic themes like maintaining physical or psychological health. In coding for intrinsic themes in high points, the coder was to ask, "What made the event important or meaningful to this person, based on the narrative?" For example, some narratives centered on teaching and education. Even though the act of teaching tends to involve making contributions to others (an intrinsic concern), coders were instructed to code only for what the individual wrote was personally meaningful about the activity of teaching. Indeed, a couple of teaching narratives emphasized the individual's delight in seeing students develop (an intrinsic concern), yet other teaching narratives emphasized the individual's status as an authority figure (an extrinsic concern). Similarly, many students wrote about getting into college; some focused on finding a congruent fit with a university they liked (intrinsic), whereas others focused on the status gained by attending the university (extrinsic). Examples of intrinsic memories appear in Appendix A.

Computing integrative memories and intrinsic memories. The variables for integrative memories and intrinsic memories were calculated first for specific-episode memories (high points, low points, turning points) and then in aggregate. For the specific episodes, the presence of an integrative theme was counted as a 1 , and its absence was counted as a 0 . The same was done for intrinsic themes. This yielded six dichotomous variables: integrative high points, intrinsic high points, integrative low points, intrin-

expressed both intrinsic and extrinsic concerns. In previous studies with similar coding protocols (e.g., Bauer \& McAdams, 2004b), we piloted coding systems with three and four categories (e.g., intrinsic, nonintrinsic, and mixed), but found that almost all narratives fell in a "mixed" category. It is important to note that narratives often emphasize one theme or another even while expressing multiple themes (McAdams, 1988). The dichotomous coding reflects this emphasis. The ability to identify this emphasis demands a narrative approach. The simple name or brief labeling of a memory (or goal) will often fail to address the underlying reasons why the memory (or goal) is important (Bauer, McAdams, \& Sakaeda, 2004). sic low points, integrative turning points, and intrinsic turning points. We also computed aggregate variables by summing the three types of integrative memories into a variable called "integrative memories" and by summing the three types of intrinsic memories into a variable called "intrinsic memories." Thus, integrative memories could have a value of $0,1,2$, or 3 , as could intrinsic memories.

\section{Nonnarrative Measures}

Maturity. The Washington University Sentence Completion Test of Ego Development (ED; Hy \& Loevinger, 1996) asks participants to complete 18 sentence stems, for example, "When a child will not join in group activities . ..," "A man's job ...," "My mother and I . . ," "A wife should ...," and "Rules are ...." Each item is scored according to guidelines and aggregated. Although these aggregated scores fall into eight levels, we used the raw aggregated scores to maximize variability. For illustrative purposes, these eight levels correspond to different levels or stages in personality development. The levels are (with Level 1 being reserved for the presocial infant who as yet lacks an ego) as follows:

2. Impulsive (passively dependent)

3. Self-protective (opportunistic)

4. Conformist (following rules)

5. Self-aware (fairness; consideration of rules)

6. Conscientious (self-evaluated standards)

7. Individualistic (respect for others' standards)

8. Autonomous (understanding of interdependence)

9. Integrated (reconciles conflicts within a broader identity)

The ED scoring guidelines, which are self-instructive, have shown high levels of reliability and internal consistency (Loevinger \& Wessler, 1970). ED was scored by a trained coder (an advanced graduate student) whose agreement with practice materials in Hy and Loevinger's (1996) training manual was greater than $85 \%$.

Well-being. We used two measures of well-being. Participants completed PWB (Ryff \& Keyes, 1995). We used the individual-dimension scores as well as the mean PWB score, aggregated from the six separate scales (see Hypothesis 3 section, above). We refer to the mean PWB score simply as PWB, whereas we explicitly state when we used analyses with individual dimensions of PWB scores. Cronbach's alpha reliabilities for PWB in the student study were Autonomy, .85; Environmental Mastery, .83; Personal Growth, .84; Positive Relationships, .84; Purpose in Life, .86; Self-Acceptance, .90; overall, .95. Alphas in the adult study were Autonomy, .85; Environmental Mastery, .83; Personal Growth, .67; Positive Relationships, .86; Purpose in Life, .70; Self-Acceptance, .91; overall, .94. We also used the SWLS (Diener et al., 1985). The SWLS is a five-item measure of overall life satisfaction. Alphas for SWLS were .87 in the student study and .86 in the adult study.

Traits. We used the Big Five Inventory (John \& Srivastava, 1999), a well-validated measure in which participants rate on a 5-point scale the degree to which each of 44 items describes one's own personality. The prompt reads, "I see myself as someone who ..." Sample descriptions include "can be tense," "is outgoing, sociable," and "is curious about many different things." Items converge on five personality traits: Neuroticism, Extraversion, Openness, Conscientiousness, and Agreeableness. In the present studies, we focused on Neuroticism, Extraversion, and Openness. 
Results

\section{Descriptive Statistics}

Frequencies for each type of memory appear in Table 1. Students' scores (mean, standard deviation) on other measures were ED (97.32, 8.94), PWB (64.11, 6.92), SWLS (24.72, 6.00), Neuroticism (3.18, 0.84), Extraversion (3.30, 0.99), and Openness (3.92, 0.71). Adults' scores were ED (97.71, 10.17), PWB (66.70, 7.60), SWLS (23.04, 7.36), Neuroticism (2.64, 0.88), Extraversion $(3.48,0.64)$, and Openness $(4.00,0.67)$. Of these measures, the student and adult samples differed in PWB and Neuroticism scores: Adults had higher PWB scores, $t(174)=2.18, p<.05$, and lower Neuroticism scores, $t(174)=-3.80, p<.001$, than students. One gender difference emerged when considering the student and adult studies together, with women having lower Neuroticism scores than men, $t(174)=2.12, p<.05$, though this relationship was not significant in either of the individual samples. Interactions of sample and gender in analyses of variance of these measures were not significant. The relationships found above did not significantly affect the relationships reported below. Finally, we note that adults' income and education levels did not correlate significantly with these measures, which supports previous research showing that higher incomes do not correlate with wellbeing beyond the poverty level (most of the participants came from a middle to upper middle socioeconomic status). In reporting the findings below, for the sake of brevity we focus on the aggregate memory variables instead of breaking them down according to high, low, and turning points (although results with these variables are reported in the tables).

\section{Correlations}

Maturity and well-being. For students, ED and PWB scores correlated significantly, but ED and SWLS scores did not. For adults, ED did not correlate significantly with either PWB or SWLS (see Table 2).

Growth memories, maturity, and well-being. Hypothesis 1 claims that integrative memories will correlate predominantly with ED scores, whereas intrinsic memories will correlate predominantly with well-being (PWB and SWLS scores). For students, ED, PWB, and SWLS scores each correlated significantly with both integrative memories and intrinsic memories (see Table 2) Turning to the adult study, ED scores correlated significantly with integrative memories. Adults' PWB scores correlated significantly with integrative memories and intrinsic memories. Adults' SWLS scores correlated significantly with intrinsic memories. Correlations with high, low, and turning points largely conformed to the patterns of the aggregate memory variables, with the notable exception that intrinsic low points did not correlate with wellbeing in the adult study (see Table 2). Overall, these correlations served the primary purpose of setting up the regression models that tested Hypotheses 1 and 2 (see below).

Growth memories and specific dimensions of PWB. Hypothesis 3 claims that integrative memories will correlate with the PWB

Table 1

Frequencies of Narrative Memories

\begin{tabular}{|c|c|c|c|c|c|c|c|c|}
\hline \multirow[b]{2}{*}{ Variable } & \multicolumn{4}{|c|}{ Student frequency } & \multicolumn{4}{|c|}{ Adult frequency } \\
\hline & 0 & 1 & 2 & 3 & 0 & 1 & 2 & 3 \\
\hline \multicolumn{9}{|c|}{ Integrative memories (total) } \\
\hline$n$ & 67 & 23 & 26 & 9 & 16 & 14 & 16 & 5 \\
\hline$\%$ & 54 & 18 & 21 & 7 & 31 & 27 & 31 & 10 \\
\hline \multicolumn{9}{|c|}{ Intrinsic memories (total) } \\
\hline$n$ & 34 & 33 & 35 & 23 & 9 & 14 & 21 & 7 \\
\hline$\%$ & 27 & 26 & 28 & 18 & 18 & 27 & 41 & 14 \\
\hline \multicolumn{9}{|c|}{ High points: Integrative } \\
\hline$n$ & 93 & 32 & & & 31 & 20 & & \\
\hline$\%$ & 74 & 26 & & & 61 & 39 & & \\
\hline \multicolumn{9}{|l|}{ High points: Intrinsic } \\
\hline$n$ & 59 & 66 & & & 17 & 34 & & \\
\hline$\%$ & 47 & 53 & & & 33 & 67 & & \\
\hline \multicolumn{9}{|c|}{ Low points: Integrative } \\
\hline$n$ & 96 & 29 & & & 39 & 12 & & \\
\hline$\%$ & 77 & 23 & & & 76 & 24 & & \\
\hline \multicolumn{9}{|l|}{ Low points: Intrinsic } \\
\hline$n$ & 83 & 42 & & & 38 & 13 & & \\
\hline$\%$ & 66 & 34 & & & 74 & 26 & & \\
\hline \multicolumn{9}{|c|}{ Turning points: Integrative } \\
\hline$n$ & 82 & 43 & & & 22 & 29 & & \\
\hline$\%$ & 66 & 34 & & & 43 & 57 & & \\
\hline \multicolumn{9}{|c|}{ Turning points: Intrinsic } \\
\hline$n$ & 57 & 68 & & & 21 & 30 & & \\
\hline$\%$ & 46 & 54 & & & 41 & 59 & & \\
\hline
\end{tabular}

Note. The scores listed under each value indicate the number of participants who had a particular frequency of a particular type of memory. The first two variables represent aggregate variables. Each of the other variables was dichotomous. 


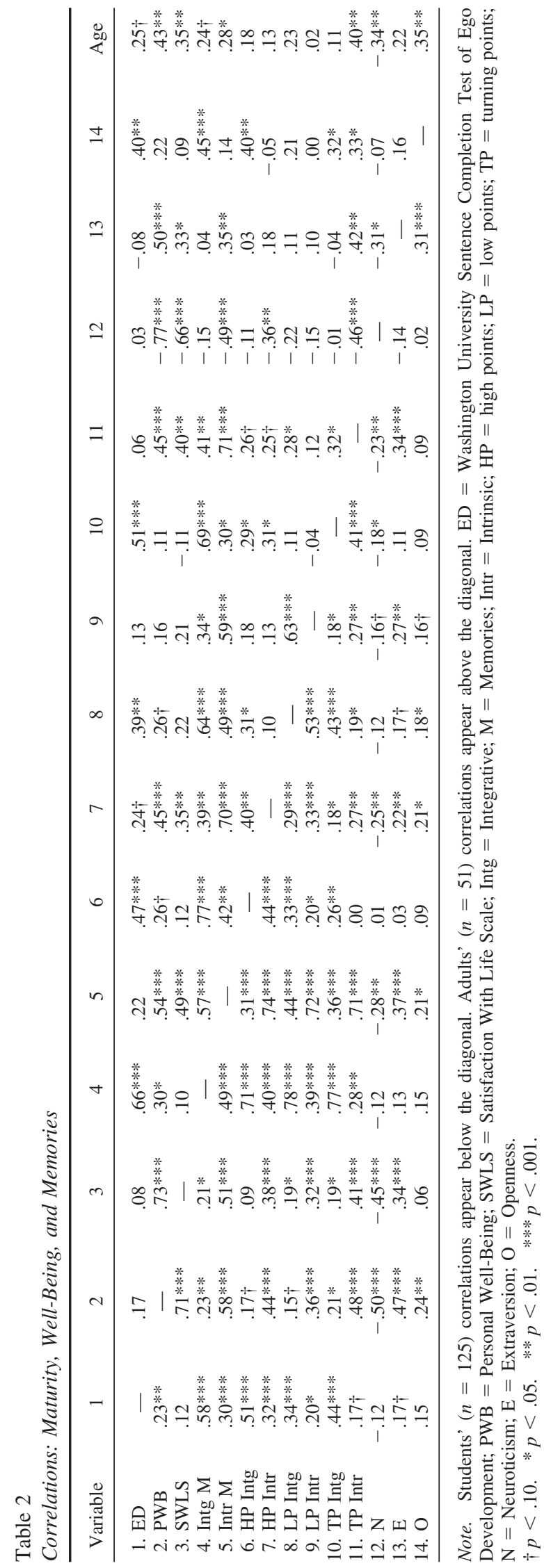

dimensions of Autonomy, Personal Growth, and Purpose in Life, whereas intrinsic memories will correlate with all six PWB dimensions. For students, integrative memories correlated significantly with three dimensions of PWB: Autonomy, Personal Growth, and Purpose in Life (see Table 3). Students' intrinsic memories correlated significantly with each of the six dimensions of PWB. For adults, integrative memories correlated significantly with the PWB dimensions of Personal Growth and (marginally) Purpose in Life (but not Autonomy). Adults' intrinsic memories correlated significantly with five of the six PWB dimensions: Environmental Mastery, Personal Growth, Positive Relationships, Purpose in Life, and Self-Acceptance (but not Autonomy).

Traits. Hypothesis 4 claims that growth memories (a narrative variable) are largely independent of broad personality traits in predicting maturity and well-being. For students, Neuroticism correlated significantly and inversely with PWB scores, SWLS scores, and intrinsic memories (see Table 2). Students' Extraversion correlated significantly with ED scores (marginally), PWB scores, SWLS scores, and intrinsic memories. Students' Openness correlated significantly with PWB scores and intrinsic memories (and notably not with ED scores). For adults, Neuroticism correlated significantly and inversely with PWB scores, SWLS scores, and intrinsic memories. Adults' Extraversion correlated significantly with PWB scores, SWLS scores, and intrinsic memories. Adults' Openness correlated significantly with ED scores and integrative memories. We ran multiple regressions to test whether traits accounted for the relationships between memories and maturity or well-being (see below).

Age. Hypothesis 5 claims that in the event that age correlates with either maturity or well-being, growth memories will in part account for that relationship. Students' ages $(M=19.8$ years, $S D=1.0 ; 90 \%$ were between 19 and 21 ) did not correlate significantly with any of the variables. Adults' ages $(M=51.7$ years, $S D=10.0$, range 30-72) correlated significantly with ED scores (marginally), PWB scores, SWLS scores, integrative memories (marginally), and intrinsic memories (see Table 2). Thus, the stage was set for mediational analyses of the relationships between age and maturity and between age and well-being (see below; Baron \& Kenny, 1986).

\section{Regressions of Maturity and Well-Being on Growth Memories}

Hypothesis 1 claims that integrative memories and intrinsic memories will map differentially onto ED and well-being scores. As mentioned, both growth memories correlated with both ED and well-being scores, especially for students. The protocol here was first to regress ED scores (and later PWB and SWLS scores) on integrative memories and intrinsic memories simultaneously. For students, integrative memories predicted ED scores significantly, but intrinsic memories did not (see Table 4). Students' intrinsic memories predicted PWB scores significantly, but integrative memories did not. Students' intrinsic memories predicted SWLS scores significantly, but integrative memories did not. Turning to the adult study, integrative memories predicted ED scores significantly, but intrinsic memories did not. Adults' intrinsic memories predicted PWB scores significantly, but integrative memories did not. Adults' intrinsic memories predicted SWLS scores significantly, but integrative memories did not. Regressions on individual 
Table 3

Correlations: Memories and Individual Dimensions of Personal Well-Being

\begin{tabular}{lcccccccc}
\hline \multicolumn{1}{c}{ Well-being dimension } & 1 & 2 & 3 & 4 & 5 & 6 & 7 & 8 \\
\hline 1. Integrative memories & - & $.57 * * *$ & .21 & .10 & $.55^{* * *}$ & .20 & $.26 \dagger$ & .16 \\
2. Intrinsic memories & $.49^{* * *}$ & - & .17 & $.44^{* * *}$ & $.38^{* *}$ & $.50^{* * *}$ & $.49^{* * *}$ & $.48^{* * *}$ \\
3. Autonomy & $.18^{*}$ & $.32^{* * *}$ & - & $.40^{* *}$ & $.52^{* * *}$ & $.34 *$ & $.31^{*}$ & $.55^{* * *}$ \\
4. Environmental Mastery & .14 & $.42^{* * *}$ & $.36^{* * *}$ & - & $.39^{* *}$ & $.42^{* *}$ & $.58^{* * *}$ & $.77^{* * *}$ \\
5. Personal Growth & $.27 * *$ & $.44^{* * *}$ & $.44^{* * *}$ & $.39^{* * *}$ & - & $.48^{* * *}$ & $.46^{* * *}$ & $.37 * *$ \\
6. Positive Relationships & .12 & $.37 * *$ & $.27^{*}$ & $.36^{* * *}$ & $.40^{* * *}$ & - & $.43^{* * *}$ & $.49^{* * *}$ \\
7. Purpose in Life & $.18^{*}$ & $.48^{* * *}$ & $.26^{* *}$ & $.55^{* * *}$ & $.50^{* * *}$ & $.34 * * *$ & - & $.69^{* * *}$ \\
8. Self-Acceptance & .14 & $.51^{* * *}$ & $.43^{* * *}$ & $.67 * * *$ & $.59^{* * *}$ & $.57^{* * *}$ & $.64 * * *$ & - \\
\hline
\end{tabular}

Note. Students' $(n=125)$ correlations appear below the diagonal. Adults' $(n=51)$ correlations appear above the diagonal.

$\dagger p<.10 . \quad * p<.05 . \quad * * p<.01 . \quad * * * p<.001$.

types of memories (high, low, and turning points) showed the same general pattern of results, with the exception in the adult study that intrinsic low points did not predict well-being (either PWB or SWLS). Thus, even though integrative memories and intrinsic memories both correlated with ED and well-being scores for both students and adults (with one exception), it appeared that integrative concerns drove the relationship between memories and ED scores, whereas intrinsic concerns drove the relationship between memories and well-being scores.

\section{Regressions of Intrinsic Memories on PWB and SWLS}

Hypothesis 2 involves the differentiation of PWB and SWLS scores in relation to intrinsic memories on the basis of their eudaimonic versus hedonic approaches to well-being. To test this, we used a somewhat unorthodox procedure. Whereas the other regression analyses in these studies regressed ED or well-being scores on the memory variables, in this case we regressed the memory variables on PWB and SWLS scores. Although this may seem counterintuitive, we emphasize that these data and the re- gression procedure itself involve correlations (i.e., PWB and SWLS are not "dependent variables," and memories are not "independent variables"). We begin with the students. Regressing intrinsic memories on PWB and SWLS scores simultaneously, we found that PWB scores predicted intrinsic memories significantly $(\beta=.44, p<.001)$ whereas SWLS scores did so marginally $(\beta=$ $.20, p<.10)$. Running the same regression for the adults, we found that PWB scores predicted intrinsic memories significantly $(\beta=$ $.39, p<.05)$, but SWLS scores did not $(\beta=.20, p>.10)$. Thus, intrinsic memories and PWB scores shared a closer relationship than did intrinsic memories and SWLS scores-a closeness that reflects a shared theoretical background in a eudaimonic rather than hedonic approach to well-being.

Although integrative memories were not part of this hypothesis, integrative memories did correlate significantly with PWB and SWLS scores in the student study (as mentioned above). We regressed integrative memories on PWB and SWLS scores simultaneously and found that neither PWB scores $(\beta=.17, p>.10)$ nor SWLS scores $(\beta=.08, p>.10)$ predicted integrative mem-

Table 4

Regressions of Maturity and Well-Being on Models of Integrative and Intrinsic Memories

\begin{tabular}{|c|c|c|c|c|c|c|}
\hline \multirow[b]{2}{*}{ Model } & \multicolumn{3}{|c|}{ Students } & \multicolumn{3}{|c|}{ Adults } \\
\hline & $\mathrm{ED}$ & PWB & SWLS & ED & PWB & SWLS \\
\hline \multicolumn{7}{|l|}{ Model 1} \\
\hline Integrative memories (aggregate) & $.57 * * *$ & -.07 & -.06 & $.79 * * *$ & -.01 & $-.26 \dagger$ \\
\hline Intrinsic memories (aggregate) & .02 & $.61 * * *$ & $.54 * * *$ & -.23 & $.54 * * *$ & $.63 * * *$ \\
\hline \multicolumn{7}{|l|}{ Model 2} \\
\hline Integrative high points & $.46^{* * *}$ & -.03 & -.10 & $.45^{* *}$ & .10 & -.02 \\
\hline Intrinsic high points & .12 & $.46 * * *$ & $.42 * * *$ & .06 & $.41 * *$ & $.36^{*}$ \\
\hline \multicolumn{7}{|l|}{ Model 3} \\
\hline Integrative low points & $.33 * * *$ & -.05 & .03 & $.51 * *$ & .28 & .16 \\
\hline Intrinsic low points & .03 & $.38 * * *$ & $.30^{* *}$ & -.19 & -.02 & .11 \\
\hline \multicolumn{7}{|l|}{ Model 4} \\
\hline Integrative turning points & $.45^{* * * *}$ & .01 & .02 & $.55^{* * * *}$ & -.04 & $-.26 \dagger$ \\
\hline Intrinsic turning points & -.01 & $.48 * * *$ & $.40 * * *$ & -.11 & $.46^{* * *}$ & $.49 * * *$ \\
\hline
\end{tabular}

Note. Betas are reported above. $R^{2}$ s follow, first by study (students, adults), then by the variable regressed (ED, PWB, SWLS), then by model number $(1,2,3$, 4). Students: ED: $.34, .28, .12, .18$. PWB: $.34, .20, .13, .23$. SWLS: $.27, .15, .10, .17$. Adults: ED: $.47, .22, .18, .28$. PWB: $.29, .21, .07, .20$. SWLS: .28, .12, .06, .23. ED = Washington University Sentence Completion Test of Ego Development; PWB = Personal Well-Being; SWLS = Satisfaction With Life Scale.

$\dagger p<.10$. $* p<.05$. *** $p<.01 . \quad * * * p<.001$. 
ories significantly. In the adult study, integrative memories correlated significantly with PWB but not SWLS scores. In summary, integrative memories corresponded to eudaimonic rather than hedonic well-being for adults, but we found no significant evidence that integrative memories were particularly geared toward either eudaimonic or hedonic well-being for students.

\section{Regressions of Maturity and Well-Being on Growth Memories and Traits}

Hypothesis 4 claims that the relations between growth memories and both maturity and well-being will be independent of traits. (Traits correlated mostly as predicted with memories, maturity, and well-being, as mentioned earlier.) For the sake of brevity, we highlight only the regression models that tested our predictionsnamely, that integrative memories and Openness would be independent predictors of ED scores, whereas intrinsic memories and the traits Neuroticism and Extraversion would be independent predictors of PWB and SWLS scores. We do not report other iterations of these regressions, because significant bivariate correlations between traits and either maturity or well-being were not found, with one exception. ${ }^{6}$ In each of the following regression models, interactions were not significant.

Single-trait models. All regressions here tested predictors simultaneously. We begin with the students. In a regression of ED scores, integrative memories predicted ED scores significantly, but Openness did not (see Table 5). Regressing PWB scores, intrinsic memories and Neuroticism (inversely) predicted PWB scores significantly and independently. In another regression of PWB scores, intrinsic memories and Extraversion predicted PWB scores significantly and independently. Regressing SWLS scores, intrinsic memories and Neuroticism (inversely) predicted SWLS scores significantly and independently. In another regression of SWLS scores, intrinsic memories predicted SWLS significantly, whereas Extraversion did so marginally. We turn now to the adults. Regressing ED scores, integrative memories predicted ED scores significantly, but Openness did not. Regressing PWB scores, intrinsic memories and Neuroticism (inversely) predicted PWB scores significantly and independently (although intrinsic memories' beta dropped from .54 to .21). In another regression of PWB scores, intrinsic memories and Extraversion predicted PWB scores significantly and independently. Regressing SWLS scores, intrinsic memories predicted SWLS scores marginally significantly, whereas Neuroticism did so significantly. In another regression of SWLS scores, intrinsic memories predicted SWLS scores significantly, but Extraversion did not. Thus, narrative memories were largely independent of individual traits in predicting maturity and well-being.

Dual-trait models. We also tested combinations of Neuroticism and Extraversion in predicting well-being. For students, we ran a model regressing PWB scores first on intrinsic memories, then adding Neuroticism, and finally adding Extraversion. We found that intrinsic memories $(\beta=.37, p<.001)$, Neuroticism (inversely; $\beta=-.37, p<.001)$, and Extraversion $(\beta=.28, p<$ $.001)$ each predicted PWB scores significantly. Regressing SWLS scores on the same model, we found that intrinsic memories $(\beta=$ $.36, p<.001$ ), Neuroticism (inversely; $\beta=-.34, p<.001$ ), and Extraversion (marginally; $\beta=.15, p<.06$ ) each predicted SWLS scores significantly. Turning to the adults, we regressed PWB
Table 5

Predicted Regressions of Maturity and Well-Being on Memories and Traits

\begin{tabular}{|c|c|c|c|c|}
\hline \multirow[b]{2}{*}{ Model } & \multicolumn{2}{|c|}{ Students } & \multicolumn{2}{|c|}{ Adults } \\
\hline & Std. $\beta$ & Adj. $R^{2}$ & Std. $\beta$ & Adj. $R^{2}$ \\
\hline \multicolumn{5}{|l|}{ 1. Regressing ED on: } \\
\hline Integrative memories & $.58 * * *$ & .33 & $.60 * * *$ & .42 \\
\hline Openness & .03 & & .13 & \\
\hline \multicolumn{5}{|l|}{ 2. Regressing PWB on: } \\
\hline Intrinsic memories & $.48 * * *$ & .45 & $.21 *$ & .61 \\
\hline Neuroticism & $-.37 * * *$ & & $-.67 * * *$ & \\
\hline \multicolumn{5}{|l|}{ 3. Regressing PWB on: } \\
\hline Intrinsic memories & $.47 * * *$ & .40 & $.41 * * *$ & .37 \\
\hline Extraversion & $.29 * * *$ & & $.36 * *$ & \\
\hline \multicolumn{5}{|l|}{ 4. Regressing SWLS on: } \\
\hline Intrinsic memories & $.42 * * *$ & .36 & $.21 \dagger$ & .45 \\
\hline Neuroticism & $-.34 * * *$ & & $-.56^{* * * *}$ & \\
\hline \multicolumn{5}{|l|}{ 5. Regressing SWLS on: } \\
\hline Intrinsic memories & $.45^{* * *}$ & .27 & $.42 * *$ & .23 \\
\hline Extraversion & $.16 \dagger$ & & .18 & \\
\hline
\end{tabular}

Note. $\quad$ Std. $=$ standardized $;$ Adj. $=$ adjusted $; \mathrm{ED}=$ Washington University Sentence Completion Test of Ego Development; PWB = Personal Well-Being; SWLS $=$ Satisfaction With Life Scale.

$\dagger p<.10$. $* p<.05$. *** $p<.01 . \quad * * * p<.001$.

scores on the same model and found that intrinsic memories did not predict PWB scores significantly $(\beta=.14, p>.10)$, whereas Neuroticism (inversely; $\beta=-.62, p<.001$ ) and Extraversion $(\beta=.26, p<.01)$ did. Regressing SWLS scores on the same model, we found that neither intrinsic memories $(\beta=.19, p>.10)$ nor Extraversion $(\beta=.09, p>.10)$ predicted PWB scores significantly, whereas Neuroticism (inversely; $\beta=-.54, p<$ .001) did. Thus, the combination of Neuroticism and Extraversion did not account for the relationship between intrinsic memories and well-being for students, but that combination did mediate the relationship between intrinsic memories and well-being for adults.

\section{Regressions of Maturity and Well-Being on Growth Memories and Age}

Hypothesis 5 claims that growth memories will account for any relationships that might emerge between age and maturity and between age and well-being (as mentioned, such relationships were found). The general protocol for these regression models was to regress ED, PWB, or SWLS scores on the relevant memory variable in Step 1 and then to add age in Step 2. This protocol tested whether age (which held at least marginal relationships with ED, PWB, and SWLS scores) continued to explain a significant portion of the variance in ED, PWB, and SWLS scores when also considering the relationship between memories and those variables.

Regressions of maturity. We regressed ED scores on integrative memories in Step 1, adding age in Step 2. We found that age

\footnotetext{
${ }^{6}$ One significant correlation emerged that was not predicted: Students' Openness correlated significantly with PWB scores. A regression of PWB scores on Openness and intrinsic memories showed that intrinsic memories, but not Openness, held its significant relation to PWB scores.
} 
no longer held its marginally significant relationship with ED scores. Integrative memories predicted ED scores significantly $(\beta=.63, p<.001)$, whereas age no longer did $(\beta=.10, p>.10)$; $\Delta R^{2}=.01$, which was not significant, $F(1,48)=.70, p>.10$. Thus, integrative memories largely mediated the marginal relationship between age and ED scores.

Regressions of well-being. First we regressed PWB scores on intrinsic memories in Step 1, adding age in Step 2. Intrinsic memories predicted PWB scores significantly $(\beta=.50, p=.001)$, as did age $(\beta=.29, p<.05) ; \Delta R^{2}=.08$, which was significant, $F(1,48)=6.05, p<.05$. We then regressed SWLS scores on the same model. We found that intrinsic memories predicted SWLS scores significantly $(\beta=.49, p<.001)$, whereas age no longer did $(\beta=.21, p>.10) ; \Delta R^{2}=.04$, which was not significant, $F(1$, $48)=2.90, p<.10$. Thus, intrinsic memories significantly mediated (though not fully) the relationship between age and SWLS scores but not between age and PWB scores.

\section{Discussion}

These findings reveal that mature people and happy people framed their autobiographical memories around relatively distinct growth orientations. Participants high in maturity emphasized the importance of having reached new levels of conceptual understanding. Participants high in well-being emphasized the importance of growing personally or interpersonally. Growth memories related to maturity and well-being in ways that reflected their roots in a eudaimonic approach to the good life. These relationships, which involved narratives of memories, were for the most part not explained by participants' broad personality traits (with two notable exceptions). Finally, adults' growth memories accounted for a significant portion of the relationship between age and maturity and between age and life satisfaction. After discussing these findings, we present a qualitative analysis of memories that were both integrative and intrinsic in an effort to shed light on why autobiographical memories relate to the good life. We also discuss the role of autobiographical memories in the good life-particularly in the intentional cultivation of it.

\section{Growth Memories, Maturity, and Well-Being}

For both students and adults, the autobiographical memories of mature participants emphasized integrating new meanings in life, whereas the memories of happy participants emphasized intrinsic or humanistic concerns. Bivariate correlations did show some overlap, especially for students, such that integrative memories also correlated significantly with well-being, and intrinsic memories also correlated significantly with maturity (noting that students' ED and PWB also correlated significantly). However, regression models showed that these "overlap" relationships no longer held when controlling for the memory that was predicted to be dominant (thereby revealing more direct, parsimonious relationships between integrative memories and maturity and between intrinsic memories and well-being). These and previous findings (Bauer \& McAdams, 2004a, 2004b; King et al., 2000) suggest that specific ways of thinking about one's life-whether interpreting the past or planning the future-correspond to specific, broad facets of personality.
On the one hand, mature people tended to frame their autobiographical memories on deepening their understanding of life by integrating new perspectives, creating new meanings, and learning general lessons. In other words, these people framed their memories around social-cognitive growth-or more specifically, around the kinds of things that theoretically foster social-cognitive development (i.e., the differentiation and integration or assimilation and accommodation of information about the self and others; Bauer \& Bonnano, 2001a; Piaget, 1970). In still other words, mature people seemed to create meaning in life events by interpreting that they learned something about life from those events.

On the other hand, happy people (again, happy in a eudaimonic sense that involves not only pleasure but also growth and connections to purposes and people beyond the individual self) tended to interpret their lives in terms of acting on intrinsic values such as personal growth, fostering meaningful relationships, and contributing to society and future generations - rather than on extrinsic or materialistic concerns such as attaining money, approval, status, and physical appearances. Research has shown that an excessive emphasis on materialistic values and goals in life corresponds to lower levels of well-being (Kasser \& Ryan, 1993, 1996). In contrast, happy people seemed to value doing things they deeply loved - that is, things that were interesting for their own sake - as well as cultivating relationships with the people they loved (and not, e.g., working for the purpose of gaining many admirers). Thus, happy people seemed to create meaning in life events by interpreting them in terms of humanistic values.

\section{Growth Memories and Eudaimonic Well-Being}

Growth memories correlated with forms of well-being derived from both the eudaimonic (PWB) and hedonic (SWLS) traditions. This is consonant with claims that both traditions contribute to a comprehensive understanding of happiness, well-being, psychological health, and the good life (Diener et al., 1998). However, growth memories were operationally defined more in the eudaimonic tradition (Ryan \& Deci, 2001). This theoretical basis was reflected empirically. Intrinsic memories correlated more strongly with PWB than with SWLS. Furthermore, integrative memories correlated significantly with dimensions of PWB that have been found to hold the weakest ties to hedonic measures, namely Autonomy, Personal Growth, and Purpose in Life. In contrast, intrinsic memories correlated significantly with all six dimensions of PWB. This is not to say that intrinsic memories are a "hedonic" measure (as witnessed in the previous finding). Rather, intrinsic memories are more likely than integrative memories to share overlapping qualities with hedonic measures. Eudaimonic and hedonic approaches to well-being have overlap (Ryan \& Deci, 2001). For example, they share the notion that one perceives one's life as good and somehow pleasurable. Yet they differ in the definition of what is good (as in a "good life"): whether that definition comprises primarily pleasure or involves more conceptually infused criteria like self-understanding and long-term growth. The eudaimonic definition of well-being seemed to more closely characterize the people in these studies who emphasized personal growth in their autobiographical memories. 


\section{Growth Memories Were Not Derivatives of Traits}

Narrative growth memories appeared not to be mere byproducts of broad personality traits in predicting maturity and well-being. There is a tendency to view broad traits-especially the Big Five-as the basic building blocks of personality (McCrae \& Costa, 1999). However, the present studies found that even though growth memories and traits were correlated, they played largely independent roles in predicting maturity and well-being (as predicted; see McAdams, 1995). This was especially noteworthy given the strong correlations between traits and well-being: Neuroticism and Extraversion each correlated with well-being around the \pm .50 level (topping at -.77 for adults' Neuroticism), yet intrinsic memories held a significant, and typically highly significant, relationship to well-being when controlling for traits. In fact, Openness and Extraversion in some cases no longer remained significant predictors of maturity and well-being (respectively) when considering growth memories. However, in the adult study, the combination of two traits-low Neuroticism and high Extraversion-did account for a significant part of the relationship between intrinsic memories and well-being. Thus, we found some evidence that the combination of traits can provide a significant portion of the information about the relation between narrative measures and well-being. This is important not only theoretically but also pragmatically, because narrative measures are much more time consuming than trait measures. However, most of the findings here suggest that simply knowing people's broad traits does not fully explain how mature and happy people frame their narrative, autobiographical memories (at least in terms of growth). In both studies, integrative memories predicted maturity more strongly than traits, notably Openness. Concerning well-being, we had three sets of findings: Traits and intrinsic memories were independent predictors of well-being in some cases, intrinsic memories mediated the relationship between traits and well-being in other cases, and traits mediated the relationship between intrinsic memories and well-being in still other cases. This points to a complex relationship between narrative and trait measures, but one overall observation stands out: Growth memories could not be simply written off as derivatives of traits in these studies. Future research is needed to examine the many ways in which narrative and trait measures relate to each other and to other measures of personality and well-being (Singer, 2004).

\section{Age and the Good Life: Memories of Mature, Happy, Older People}

Older adults were more likely than younger adults to have high levels of maturity (marginally) and well-being. Yet older adults were also more likely (at least marginally) to have growth memories. We found that integrative memories accounted in part for the marginal relationship between age and maturity, and intrinsic memories accounted in part for the relationship between age and SWLS. In other words, older adults were more likely than younger adults to have high levels of both maturity and life satisfaction, but this fact was in part explained by the fact that older adults were more likely to interpret their memories in terms of growth. However, intrinsic memories and age were independent predictors of PWB. In a broader sense, we found some evidence that relationships between age and the good life had more to do with older participants' psychological interpretations than with chronological age. These findings contribute to the growing body of research showing that personality factors account for relationships between age and personality development (Mroczek \& Kolarz, 1998; though see notes below on the cross-sectional nature of this study) — and notably that growth-oriented goals and memories account for those relationships (Bauer \& McAdams, 2004a; Sheldon \& Kasser, 2001).

\section{The Good Life: Growth-Memory Scripts of Mature, Happy People}

We were particularly interested in participants who appeared to be living the good life, that is, those who had high levels of both maturity and well-being. It was highly likely that mature, happy people in these studies had memories that were both integrative and intrinsic. In other words, when interpreting any one life event, mature, happy participants were likely to emphasize two concerns: (a) coming to a greater conceptual understanding (b) of themselves and their relationships. Such a portrait of the mature, happy person has a parallel in Rogers's (1961) "fully functioning person," who has, notably, two similar concerns: to gain (a) a more complex understanding (b) of his or her inner life. Like Rogers (1961), King (2001; King et al., 2000) has claimed that such a person aims toward living out the fuller properties of the good life. Our observations suggest that the people who approximate this fully functioning person are those who strive toward a deeper, more complex understanding of the most intrinsically meaningful people and things in their lives.

To get a better sense of the memory narratives of mature, happy people, we present three growth scripts that emerged in memories that were simultaneously integrative and intrinsic (see examples in Appendix B). The script for integrative-intrinsic high points emphasizes the realization of a personally meaningful insight rather than only an intense experience of some positive emotion (although this was typically present also). Such high points often expressed a sense of heightened meaningfulness in life or the transcending of a previous conceptualization of self (e.g., one's connection to purposes or people beyond oneself). The script for integrative-intrinsic low points conveys a concern for learning general lessons as opposed to dwelling only on the pain involved. In connection with these first two scripts, recent articles have provided alternative yet compatible ways of studying how people gain insights and learn lessons via narratives of autobiographical memories (Bauer \& McAdams, 2004b; Blagov \& Singer, 2004; Bluck \& Gluck, 2004; King \& Raspin, 2004; Thorne, McLean, \& Lawrence, 2004; Woike \& Matic, 2004). Finally, the script for integrative-intrinsic turning points conveys a concern for personal development or transformation rather than just the fact of a change in life. For turning points, it is important to note that development involves a pattern of change, not just change itself (e.g., changing from one mood or life situation to another is generally not considered as constituting development).

For each type of memory just described, the former interpretation (insight, lessons, development) represents an interpretation of an event (high, low, or turning point) in terms of growth, whereas the latter interpretation (pleasure, pain, change) represents an interpretation in terms of safety, preservation, or conservation. Similarly, Maslow (1968) claimed that events in one's life elicit a 
personal orientation toward either growth or safety. This orientation is always a matter of subjective interpretation, whether the event might seem ostensibly to be the greatest or the worst of experiences. Perhaps the most powerful examples of the role of interpretation come in the form of low points. In the adult study, several participants described a low point involving marital divorce. Naturally enough, each of these participants mentioned the great difficulties involved. Yet some participants emphasized that they learned an important lesson or that they otherwise grew from their troubles, whereas others focused only on their pain. Other examples of the notion of growth and meaning despite pain and trauma include Frankl's (1946/1984) portrayal of Holocaust survivors, whose sense of purpose transformed aspects of an otherwise horrifying experience, as well as recent research on personal growth amid trauma and loss (Bauer \& Bonnano, 2001b; Calhoun $\&$ Tedeschi, 2001; Woike \& Matic, 2004). Such examples point to the eudaimonic qualities of well-being - a happiness that includes an understanding of life in terms of growth and broader frames of meaning rather than in terms of merely pleasure versus pain.

\section{Implications for Intentional Self-Development}

We view these findings as contributing to an understanding of intentional self-development (e.g., Brandtstadter, 1999). Research often portrays personality as a byproduct of the external forces of nature and nurture. Yet research in recent years has begun pointing to the role of the individual in his or her own development. One of the notable venues of this work involves the ways individuals plan their future (via goals) and interpret their past (via memories), especially in personal goals and especially life stories. Narratives reveal how a person integrates intentions and various, often competing, motivations into a coherent story of his or her life over time or into a coherent plan of action (Bruner, 1990; Conway \& Plydell-Pearce, 2000; McAdams, 1993, 2001; Singer \& Salovey, 1993). It stands to reason that the intentions for and interpretations of one's life actually help create maturity and well-being in life. After all, whether one finds conceptual meaning or well-being in an event is a matter of interpretation: Even low points in life can bring heightened meaning and eventual well-being in life, depending on the person's perception of such events; some people interpret low points as developmental opportunities (Bauer \& Bonanno, 2001b; Bluck \& Gluck, 2004; Calhoun \& Tedeschi, 2001). To the degree that meaning and well-being result from interpretations rather than brute facts of life events, the individual is in the position to intentionally guide the meaning and well-being in his or her life by interpreting and planning that life in particular ways. Perhaps the "hard road to the good life" (King, 2001, p. 51) is paved in part with autobiographical memories (and personal goals) that are interpreted in terms of conceptually integrating one's intrinsic interests.

\section{Limitations and Directions}

We have several concerns about the interpretations of these studies. First, we note that this study was correlational and that causation between variables was not implied. This note is especially important with regard to the regression analyses and the previous Discussion section. The language of regressions (with their "predictors," "effects," etc.) often sounds causal. It is impor- tant to keep in mind that regressions are correlative and that only a study's design can allow for investigations of causality. Thus, the memory variables may have caused maturity and well-being, maturity and well-being may have caused the memory variables, or a third set of phenomena may have caused both. Also, our discussion of the implications for intentional self-development deals with causal relationships, so we wish to emphasize that we are suggesting possibilities for research in this area. Second, our analyses with age involved cross-sectional, not longitudinal, research. Therefore, we are careful not to claim that "older people grew happier as they aged," because our data did not chart the well-being of individuals over time. All we can claim is that the older participants in this study were happier and were marginally more mature than the younger participants. Such differences may have been a result of cohort differences. Future research with longitudinal data could track how people's intentions (expressed in goals and memories) lead to particular forms of personality development. Third, the samples in these studies came from relatively privileged populations, which may have influenced not only the types of events recalled in the autobiographical memories but also the value orientations toward those events. Finally, a frequent argument against narrative research as scientifically legitimate is that narrative variables are based on "mere" or "biased" perceptions of people's lives. We view this position as invalid, partly because subjective perceptions can in fact be studied systematically and in accord with the standards of normative science. In addition, it is important to keep in mind that people base their life decisions on subjective perceptions rather than on more objective standards (Kahneman, 2003; Wirtz, Kruger, Scollon, \& Diener, 2003). In this regard, systematic narrative research can offer much to psychological science (see Singer, 2004).

\section{Conclusions}

The main message of these studies is that specific ways of interpreting the important events in one's life correspond to specific facets of the good life-maturity and well-being. People who valued conceptual integration in their autobiographical memories seemed to be more mature in their capacity for social-cognitive meaning making, whereas people who valued intrinsic or humanistic interests seemed to be happier-both in a eudaimonic and a hedonic sense (but especially in the former). These findings could not be explained by simply knowing people's broad personality traits, for the most part. Older adults appeared more likely than younger adults to be living the good life, yet that was partially explained by the fact that older people were more likely to interpret their past in terms of growth. These findings have implications for the role of narrative memories in personality development and for the intentional development of maturity and well-being.

\section{References}

Baerger, D. R., \& McAdams, D. P. (1999). Life story coherence and its relation to psychological well-being. Narrative Inquiry, 9, 69-96.

Baron, R. M., \& Kenny, D. A. (1986). The moderator-mediator variable distinction in social psychological research: Conceptual, strategic, and statistical considerations. Journal of Personality and Social Psychology, 51, 1173-1182.

Bauer, J. J., \& Bonanno, G. A. (2001a). Continuity amid discontinuity: 
Bridging one's past and present in stories of conjugal bereavement. Narrative Inquiry, 11, 123-158.

Bauer, J. J., \& Bonanno, G. A. (2001b). Doing and being well (for the most part): Adaptive patterns of narrative self-evaluation during bereavement. Journal of Personality, 69, 451-482.

Bauer, J. J., \& McAdams, D. P. (2004a). Growth goals, maturity, and well-being. Developmental Psychology, 40, 114-127.

Bauer, J. J., \& McAdams, D. P. (2004b). Personal growth in adults' stories of life transitions. Journal of Personality, 72, 573-602.

Bauer, J. J., McAdams, D. P., \& Sakaeda, A. R. (2004). The crystallization of desire $v$. discontent in narratives of major life decisions. Manuscript under review.

Blagov, P. S., \& Singer, J. A. (2004). Four dimensions of self-defining memories (specificity, meaning, content, and affect) and their relationships to self-restraint, distress, and repressive defensiveness. Journal of Personality, 72, 481-512.

Bluck, S., \& Gluck, J. (2004). Making things better and learning a lesson: Experiencing wisdom across the lifespan. Journal of Personality, 72, 543-572.

Brandtstadter, J. (1999). The self in action and development: Cultural, biosocial, and ontogenetic bases of intentional self-development. In J. Brandtstadter \& R. M. Lerner (Eds.), Action and self-development: Theory and research through the life span (pp. 37-66). Thousand Oaks, CA: Sage.

Bruner, J. (1990). Acts of meaning. Cambridge, MA: Harvard University Press.

Bursik, K. (1991). Adaptation to divorce and ego development in adult women. Journal of Personality and Social Psychology, 60, 300-306.

Calhoun, L. G., \& Tedeschi, R. G. (2001). Posttraumatic growth: The positive lessons of loss. In R. A. Neimeyer (Ed.), Meaning reconstruction and the experience of loss (pp. 157-172). Washington, DC: American Psychological Association.

Charles, S. T., Reynolds, C. A., \& Gatz, M. (2001). Age-related differences and change in positive and negative affect over 23 years. Journal of Personality and Social Psychology, 80, 136-151.

Conway, M. A., \& Plydell-Pearce, C. W. (2000). The construction of autobiographical memories in the self-memory system. Psychological Review, 107, 261-288.

Damon, W., \& Hart, D. (1988). Self-understanding in childhood and adolescence. Cambridge, England: Cambridge University Press.

Deci, E. L., \& Ryan, R. M. (2000). The "what" and "why" of goal pursuits: Human needs and the self-determination of behavior. Psychological Inquiry, 11, 227-268.

Diener, E., Emmons, R. A., Larson, R. J., \& Griffen, S. (1985). The Satisfaction With Life Scale. Journal of Personality Assessment, 49, 71-75.

Diener, E., Sapyta, J. J., \& Suh, E. (1998). Subjective well-being is essential to well-being. Psychological Inquiry, 9, 33-37.

Erikson, E. H. (1994). Childhood and society. New York: Norton. (Original work published 1950)

Flanagan, O. (1991). Varieties of moral personality: Ethics and psychological realism. Cambridge, MA: Harvard University Press.

Frankl, V. E. (1984). Man's search for meaning. New York: Washington Square Press. (Original work published 1946)

Helson, R., \& Roberts, B. W. (1994). Ego development and personality change in adulthood. Journal of Personality and Social Psychology, 66, 911-920.

Helson, R., \& Wink, P. (1992). Personality change in women from the early 40s to the early 50s. Psychology and Aging, 7, 46-55.

Hy, L. X., \& Loevinger, J. (1996). Measuring ego development (2nd ed.). Mahwah, NJ: Erlbaum.

John, O. P., \& Srivastava, S. (1999). The Big Five trait taxonomy: History, measurement, and theoretical perspectives. In L. A. Pervin \& O. P. John
(Eds.), Handbook of personality: Theory and research (2nd ed., pp. 102-138). New York: Guilford Press.

Kahneman, D. (2003). A perspective on judgment and choice: Mapping bounded rationality. American Psychologist, 58, 697-720.

Kasser, T., \& Ryan, R. M. (1993). A dark side of the American dream: Correlates of financial success as a central life aspiration. Journal of Personality and Social Psychology, 65, 410-422.

Kasser, T., \& Ryan, R. M. (1996). Further examining the American dream: Well-being correlates of intrinsic and extrinsic goals. Personality and Social Psychology Bulletin, 22, 281-288.

King, L. A. (2001). The hard road to the good life: The happy, mature person. Journal of Humanistic Psychology, 41, 51-72.

King, L. A., \& Napa, C. K. (1998). What makes a life good? Journal of Personality and Social Psychology, 75, 156-165.

King, L. A., \& Raspin, C. (2004). Lost and found possible selves, subjective well-being, and ego development in divorced women. Journal of Personality, 72, 603-632.

King, L. A., Scollon, C. K., Ramsey, C., \& Williams, T. (2000). Stories of life transition: Subjective well-being and ego development in parents of children with Down syndrome. Journal of Research in Personality, 34, 509-536.

Loevinger, J. (1976). Ego development. San Francisco: Jossey-Bass.

Loevinger, J., \& Wessler, R. (1970). Measuring ego development: I. Construction and use of a sentence completion test. San Francisco: Jossey-Bass.

Maslow, A. H. (1968). Toward a psychology of being. New York: Van Nostrand Reinhold.

McAdams, D. P. (1988). Power, intimacy, and the life story: Personological inquiries into identity. New York: Guilford Press.

McAdams, D. P. (1993). The stories we live by: Personal myths and the making of the self. New York: Morrow.

McAdams, D. P. (1995). What do we know when we know a person? Journal of Personality, 63, 365-396.

McAdams, D. P. (2001). The psychology of life stories. Review of General Psychology, 5, 100-122.

McAdams, D. P., Diamond, A., de St. Aubin, E., \& Mansfield, E. D. (1997). Stories of commitment: The psychosocial construction of generative lives. Journal of Personality and Social Psychology, 72, 678694

McAdams, D. P., Reynolds, J., Lewis, M., Patten, A. H., \& Bowman, P. J. (2001). When bad things turn good and good things turn bad: Sequences of redemption and contamination in life narrative and their relation to psychosocial adaptation in midlife adults and in students. Personality and Social Psychology Bulletin, 27, 474-485.

McCrae, R. R., \& Costa, P. T. (1999). A five-factor theory of personality. In L. A. Pervin \& O. P. John (Eds.), Handbook of personality: Theory and research (2nd ed., pp. 139-153). New York: Guilford Press.

McGregor, I., \& Little, B. R. (1998). Personal projects, happiness, and meaning: On doing well and being yourself. Journal of Personality and Social Psychology, 74, 494-512.

Mroczek, D. K., \& Kolarz, C. M. (1998). The effect of age on positive and negative affect: A developmental perspective on happiness. Journal of Personality and Social Psychology, 75, 1333-1349.

Myers, D. G. (1992). The pursuit of happiness. New York: Avon.

Neugarten, B. L. (1979). Time, age, and the life cycle. American Journal of Psychiatry, 136, 887-894.

Piaget, J. (1970). Piaget's theory. In P. Mussen (Ed.), Carmichael's manual of child psychology (pp. 703-732). New York: Wiley.

Rogers, C. R. (1961). On becoming a person. Boston: Houghton Mifflin. Ryan, R. M., Chirkov, V. I., Little, T. D., Sheldon, K. M., Timoshina, E., \& Deci, E. L. (1999). The American dream in Russia: Extrinsic aspirations and well-being in two cultures. Personality and Social Psychology Bulletin, 25, 1509-1524.

Ryan, R. M., \& Deci, E. L. (2001). On happiness and human potentials: A 
review of research on hedonic and eudaimonic well-being. Annual Review of Psychology, 52, 141-166.

Ryff, C. D., \& Keyes, C. L. M. (1995). The structure of psychological well-being revisited. Journal of Personality and Social Psychology, 69, 719-727.

Ryff, C. D., \& Singer, B. (1998). The contours of positive human health. Psychological Inquiry, 9, 1-28.

Schmutte, P. S., \& Ryff, C. D. (1997). Personality and well-being: Reexamining methods and meanings. Journal of Personality and Social Psychology, 73, 549-559.

Sheldon, K. M., \& Kasser, T. (1995). Coherence and congruence: Two aspects of personality integration. Journal of Personality and Social Psychology, 68, 531-543.

Sheldon, K. M., \& Kasser, T. (2001). Getting older, getting better? Personal strivings and psychosocial maturity across the life-span. Developmental Psychology, 34, 491-501.

Singer, J. A. (2004). Narrative identity and meaning-making across the adult lifespan: An introduction. Journal of Personality, 72, 437-460.

Singer, J. A., \& Salovey, P. (1993). The remembered self: Emotion and memory in personality. New York: Free Press.

Thorne, A., McLean, K. C., \& Lawrence, A. M. (2004). When remembering is not enough: Reflecting on self-defining memories in late adolescence. Journal of Personality, 72, 513-542.

Turiel, E., Smetana, J. G., \& Killen, M. (1991). Social contexts in social cognitive development. In W. M. Kurtines \& J. L. Gewirtz (Eds.), Handbook of moral behavior and development (pp. 307-332). Hillsdale, NJ: Erlbaum.

Vaillant, G. E. (1977). Adaptation to life. Cambridge, MA: Harvard University Press.

Vaillant, G. E., \& McCullough, L. (1987). The Washington University Sentence Completion Test compared with other measures of adult ego development. American Journal of Psychiatry, 144, 1189-1194.

Wertsch, J. V. (1991). Voices of the mind: A sociocultural approach to mediated action. Cambridge, MA: Harvard University Press.

Westenberg, P. M., \& Block, J. (1993). Ego development and individual differences in personality. Journal of Personality and Social Psychology, 65, 792-800.

Wirtz, D., Kruger, J., Scollon, C. N., \& Diener, E. (2003). What to do on spring break? The role of predicted, on-line, and remembered experience in future choice. Psychological Science, 14, 520-524.

Woike, B. A., Gershkovich, I., Piorkowski, R., \& Polo, M. (1999). The role of personality motives in the content and structure of autobiographical memories. Journal of Personality and Social Psychology, 81, 935-945.

Woike, B., \& Matic, D. (2004). Cognitive complexity in response to traumatic experience. Journal of Personality, 72, 633-657.

Youniss, J. (1980). Parents and peers in social development: A SullivanPiaget perspective. Chicago: University of Chicago.

\section{Appendix A}

\section{Narrative Examples}

Each narrative memory was coded as either integrative or nonintegrative and as either intrinsic or nonintrinsic. Thus, any one narrative could be categorized as integrative and intrinsic, integrative and nonintrinsic, nonintegrative and intrinsic, or nonintegrative and nonintrinsic. In the interest of space, we present examples of these four categories. However, for each excerpt, we provide a separate rationale for the coding of the two dimensions (integrative-nonintegrative and intrinsic-nonintrinsic). For the sake of comparison, all excerpts come from narratives of high points in life.

\section{Integrative and Intrinsic}

I was by the lake at night.... I was able to formulate all my values and beliefs into one comprehensive system .... At that moment I understood and more importantly felt my relationship with the rest of the living world.

Explanation: This narrative was coded as integrative because it emphasized the integration of values and coming to a particular understanding about life. The narrative was coded as intrinsic because it dealt with the person's relationship to others in a personally meaningful way.

\section{Integrative and Nonintrinsic}

My first trip to Europe ... I celebrated my 38th birthday ... . Things were changed. I became a bird freed from a cage, a bird who could fly and did fly often .... I had seen the enlarged panorama from the peak.

Explanation: This narrative was coded as integrative because it emphasized seeing life from a new perspective. This narrative was coded as nonintrinsic because it did not explicitly explain that the new perspective was important for intrinsic reasons (e.g., it did not mention that the new perspective contributed to personal growth, to meaningful relationships, or to contributing to society).

Nonintegrative and Intrinsic

It was the birth of my son .... I was so joyful that he was born . . . The motherhood excitement set in. There was never any postpartum depression; my life was now complete ... no fears, no worries, only vast joy.

Explanation: This narrative was coded as nonintegrative because it made no explicit reference to gaining new perspectives, to learning, or to exploration. The narrative was coded as intrinsic because it made explicit reference to the joy and meaningfulness of a meaningful relation (as well as dealing with the development of future generations).

\section{Nonintegrative and Nonintrinsic}

My daughter's bat mitzvah ... our whole family was very proud of her ... the months of preparing for the event were very strenuous both emotionally and financially. It is certainly a big relief that it is over.

Explanation: This narrative was coded as nonintegrative because it made no explicit reference to gaining new perspectives, to learning, or to exploration. This narrative was coded as nonintrinsic because it emphasized not the meaningfulness of the relationship with the daughter but rather the approval of others, financial strain, and the desire to be finished with the event (underscoring the event's extrinsic role in the participant's life). 


\section{Appendix B}

Scripts for Growth Memories

\begin{tabular}{|c|c|c|}
\hline \multirow{2}{*}{$\begin{array}{l}\text { Memory: growth versus } \\
\text { safety orientations }\end{array}$} & \multicolumn{2}{|c|}{ Examples } \\
\hline & Growth script & Safety script \\
\hline $\begin{array}{l}\text { High point: Insight versus } \\
\text { pleasure }\end{array}$ & $\begin{array}{l}\text { I realized what to do with my life. } \\
\text { I discovered my place in the } \\
\text { universe. }\end{array}$ & $\begin{array}{l}\text { It was the most wonderful experience } \\
\text { of my life. } \\
\text { I finally got what I deserved. }\end{array}$ \\
\hline $\begin{array}{l}\text { Low point: Lesson versus } \\
\text { pain }\end{array}$ & $\begin{array}{l}\text { I found out how to make our } \\
\text { relationship better. } \\
\text { I learned I had strength I never } \\
\text { knew I had. }\end{array}$ & $\begin{array}{l}\text { I hope that never happens again. } \\
\text { I learned not to (do that) again. }\end{array}$ \\
\hline $\begin{array}{l}\text { Turning point: } \\
\text { Development versus } \\
\text { change }\end{array}$ & $\begin{array}{l}\text { I came to understand what's } \\
\text { important in life. } \\
\text { I grew. We can relate to each } \\
\text { other better since then. }\end{array}$ & $\begin{array}{l}\text { Everything was different after that. } \\
\text { I'm a different person. } \\
\text { Things will never be the same. }\end{array}$ \\
\hline
\end{tabular}

Received February 24, 2004

Revision received July 27, 2004

Accepted August 17, 2004 